\title{
Relação entre o tratamento de esgoto sanitário e a taxa de mortalidade infantil em quatro municípios do Rio Grande do Sul
}

Evandro Silva dos Santos ${ }^{1}$

Judite Sanson Bem²

\begin{abstract}
Resumo
A preocupação com o uso adequado dos recursos hídricos é um fator crescente. Discussões envolvendo formas e tecnologias que garantam a preservação da água são cada vez mais frequentes nos diversos meios, sejam sociais, profissionais ou acadêmicos. Através de um levantamento quantitativo de dados e as relações entre variáveis, de natureza aplicada, bem como o uso de documentos, feito a partir da consulta e pesquisa de referenciais teóricos publicados, este trabalho apresenta uma análise dos dados secundários. Estes dados são disponibilizados pelo IBGE, Agência Nacional de Águas, Sistema Nacional de Informações sobre Saneamento e Sistema Nacional de Recursos Hídricos, comparativamente de 4 municípios do estado do Rio Grande do Sul, Porto Alegre, Canoas, Esteio e Gravataí. Essas análises buscam identificar pontos relevantes nesses municípios, como a relação entre a "População total atendida com esgotamento sanitário" e o "Índice de coleta de esgoto" e, também, a relação entre o "Índice de coleta de esgoto" e a "Taxa de mortalidade infantil", com dados compilados para comparar as informações de 2012 a 2107. Verificou-se, através de regressão linear, uma forte correlação entre essas variáveis, ou seja, quanto maior o índice de esgotos com coleta e tratamento, menor é a Taxa de mortalidade infantil registrada, na amostra de municípios analisados.
\end{abstract}

Palavras-chave: Esgotamento sanitário; Mortalidade Infantil; Investimento; Saneamento.

\section{The relationship between sanitary sewage treatment, sanitation and the infant mortality rate in four municipalities in Rio Grande do Sul}

\begin{abstract}
The concern with the adequate use of water resources is an increasing factor. Discussions involving forms and technologies that guarantee the preservation of water are increasingly frequent in different media, whether social, professional or academic. Through a quantitative survey of data and the relationships between variables, of an applied nature, as well as the use of documents, made from the consultation and research of published theoretical references, this work presents an analysis of secondary data. This data is provided by IBGE, National Water Agency, National Sanitation Information System and National Water Resources System, compared to 04 municipalities in the state of Rio Grande do Sul, Porto Alegre, Canoas, Esteio and Gravataí. Such analyzes seek to identify relevant points such as the ratio between the "Total population served with sanitary sewage" and the "Sewage collection index" and the relationship between the "Sewage collection index" and the "Infant mortality rate", in these municipalities with compiled data comparing information from 2012 to 2107. There was, through linear regression, a strong correlation between these variables, that is, the higher the sewage rate with collection and treatment, the lower the registered infant mortality rate, in the sample of municipalities analyzed.
\end{abstract}

Keywords: Sewage, Infant Mortality, Investment, Sanitation

\footnotetext{
1 Mestrando do programa de Pós-Graduação em Avaliação de Impactos Ambientais da Universidade LaSalle (UniLaSalle). evandro.santos0044@unilasalle.edu.br

2 Doutora em História Íbero Americana (PUCRS) e Pós-Doutora em Economia da Cultura (UFRGS). Professora da Universidade de Caxias do Sul e do Mestrado Profissional em Memória Social e Bens Culturais da UniLasalle. jsanson@terra.com.br
} 


\section{Introdução}

A preocupação com o uso dos recursos hídricos é um fator presente. Discussões envolvendo formas e tecnologias que garantam a preservação da água são freqüentes nos meios, sejam sociais, profissionais ou acadêmicos (ANA, 2018; TUNDISI, 2008). Estima-se que $71 \%$ da superfície do planeta é coberta por água e desta, aproximadamente, 97,5\% é salgada e 1,8\% é inacessível nas geleiras e apenas $0,8 \%$ consiste em água doce disponível (ANA, 2018).

Brião et. all. (2014) comenta que com o advento da revolução industrial, o aumento das cidades, a contaminação dos reservatórios e a distribuição irregular fizeram e fazem com que várias regiões sofram com problemas de água potável no Brasil e no mundo. O Brasil possui 12\% do volume total do Planeta, e isso cria uma falsa sensação de que a água estará sempre disponível (MOREIRA, 2019).

O tratamento de esgotos é um assunto de interesse devido os impactos que são causados quando ocorre um gerenciamento inadequado dos mesmos. Assim, tem-se notado uma tendência crescente em buscar alternativas que levem a soluções no que se refere às tecnologias utilizadas para tratamento de seus efluentes líquidos (TAMBOSI, 2005).

O déficit de atendimento dos serviços de esgotamento sanitário no Brasil tem resultado em parcela significativa de esgotos sem tratamento e sem destinação adequada, por vezes dispostos diretamente nos corpos d'água, comprometendo a qualidade das águas para diversos usos, com implicações danosas à saúde pública e ao equilíbrio do meio ambiente.

Percebe-se, por meio revisão da literatura, a indicação de que os serviços de abastecimento de água e de esgotamento sanitário possuem relação direta com a mortalidade infantil, assim como as questões socioeconômicas. Ainda, baseado nas informações dos referenciais consultados, é possível observar que as regiões que possuem maiores índices de serviços inadequados de água e esgoto possuem maior mortalidade infantil (SILVA \& ESPERIDIÃO, 2017).

Segundo dados da Organização Mundial da Saúde (OMS), aproximadamente 1,5 milhão de crianças menores de 5 anos acabam morrendo anualmente por causa da doença relacionadas à falta de esgotamento sanitário. Ainda podemos salientar que a mesma OMS já mostrou que para cada $R \$ 1,00$ investido em saneamento economiza-se $R \$ 4,00$ em saúde (OMS, 2019).

De acordo com a pesquisadora Denise Kronemberger, a pedido do Instituto Trata Brasil, que avaliou a relação entre saúde e saneamento e seus impactos nos 100 maiores municípios do Brasil, entre 2008 e 2011, identificou-se que nas cidades analisadas foram registradas 28.594 
internações de crianças de até 5 anos, ou seja, 53\% do total das internações no Brasil (54.339). É importante mencionar que o custo total de internações é de cerca de $\mathrm{R} \$ 140$ milhões por ano ao Sistema Único de Saúde (BRASIL, 2016).

Na Figura 1 verifica-se os principais índices de cobertura do sistema de esgotos no Brasil, de acordo com o Atlas Esgotos (2017), onde 61,4\% destes são coletados e 42,6\% são coletados e tratados.

Figura 1 - Índices de cobertura de esgotos no Brasil em 2017

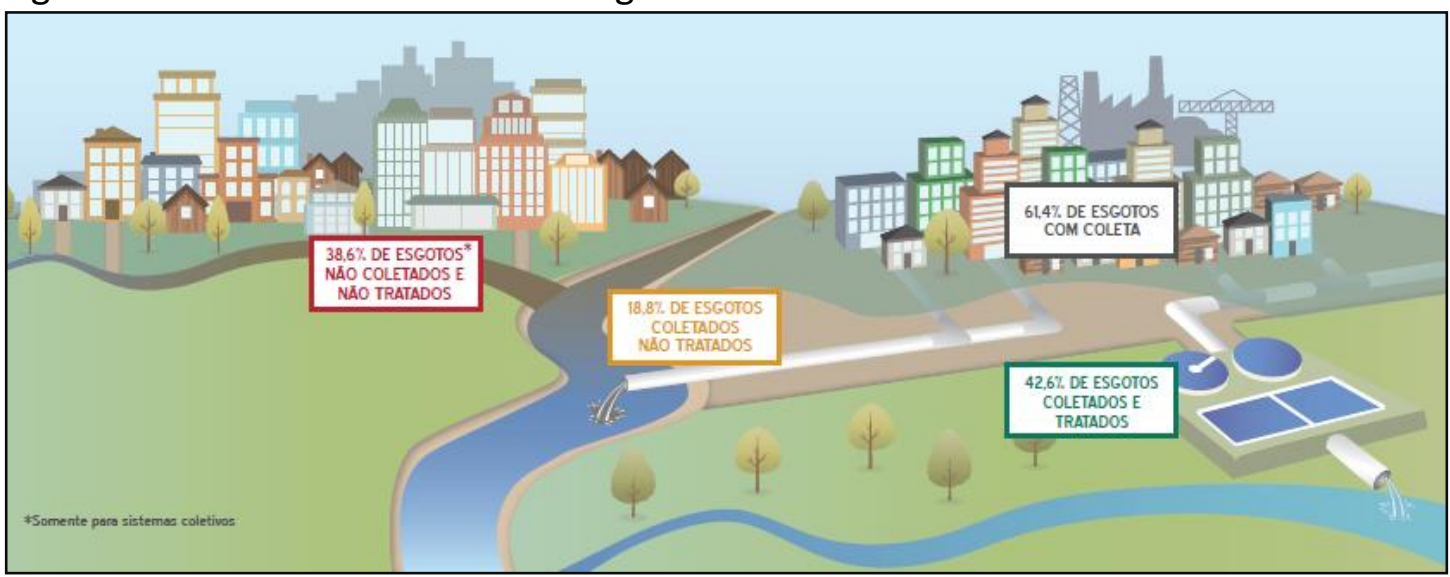

Fonte: adaptado Atlas Esgoto, 2017

A pesquisa considerou a Região Metropolitana do Estado do Rio Grande do Sul como "alvo" da avaliação, dentre eles 04 municípios mais especificamente. A escolha por estes municípios, Porto Alegre, Canoas, Esteio e Gravataí, levou em consideração alguns indicadores: Porto Alegre como a cidade de maior população e capital do estado do Rio Grande do Sul e três cidades médias próximas a capital e entre si, com o uso de bacias hidrográficas comuns, nas quais ações adotadas em um determinado município podem gerar reflexos nas demais.

Este artigo está dividido em sessões além desta Introdução. Primeiramente a revisão de literatura sobre o tema, logo após a metodologia e a análise dos dados. Considerações Finais e Referências são as últimas etapas deste artigo.

\section{Revisão teórica}

Conforme Suzin (2018) em 2017 existiam 293 cidades no estado do Rio Grande do Sul com Plano de Saneamento Básico, sendo este resultado 350\% superior a última pesquisa realizada em 2011 pelo IBGE, quando apenas 65 municípios tinham políticas definidas ou em fase de definição. 
Ainda, segundo a Pesquisa de Informações Básicas Municipais de 2017, 58,9\% das cidades gaúchas diziam ter políticas para saneamento e 13,8\% - correspondente a 69 cidades, ainda estavam elaborando suas políticas próprias na área, e 27,3\% das cidades não dispunham de políticas voltadas a este assunto (SUZIN, 2018).

Mas o saneamento, em si, além de ser uma infraestrutura básica a qualquer região é uma engrenagem necessária aos indicadores de mortalidade da mesma. A importância dos serviços de saneamento, e entre estes o esgotamento sanitário, é seu reflexo direto na qualidade de vida da população envolvida à medida que reduz doenças como à diarreia, verminoses entre outras e acrescenta-se seu impacto sobre o meio ambiente.

Conforme Menezes e Uchoa (2011), no que se refere à mortalidade infantil, o saneamento é um fator importante na diminuição dos óbitos, sendo um dos indicadores para este acompanhamento a Taxa de Mortalidade Infantil (TMI). Esta pode ser vista como um sumário da qualidade de vida que prevalece em uma determinada população, permitindo comparar os níveis em locais distintos. A correlação entre acesso da população a serviços de saneamento básico e a TMI é um fato conhecido, além do que autores propõem a relação entre o risco de morte em crianças menores de um ano, qualidade da água e sistema de esgotamento sanitário.

A compreensão das relações entre saneamento, saúde e ambiente constitui etapa fundamental no desenvolvimento de um planejamento de sistemas de abastecimento de água e de esgotamento sanitário (SOARES et. all, 2002). A Figura 2 apresenta de forma sucinta as relações existentes no ciclo urbano básico de abastecimento, uso e descarte da água como efluente.

Figura 2 - Ciclo urbano básico de abastecimento, uso e descarte da água como efluente

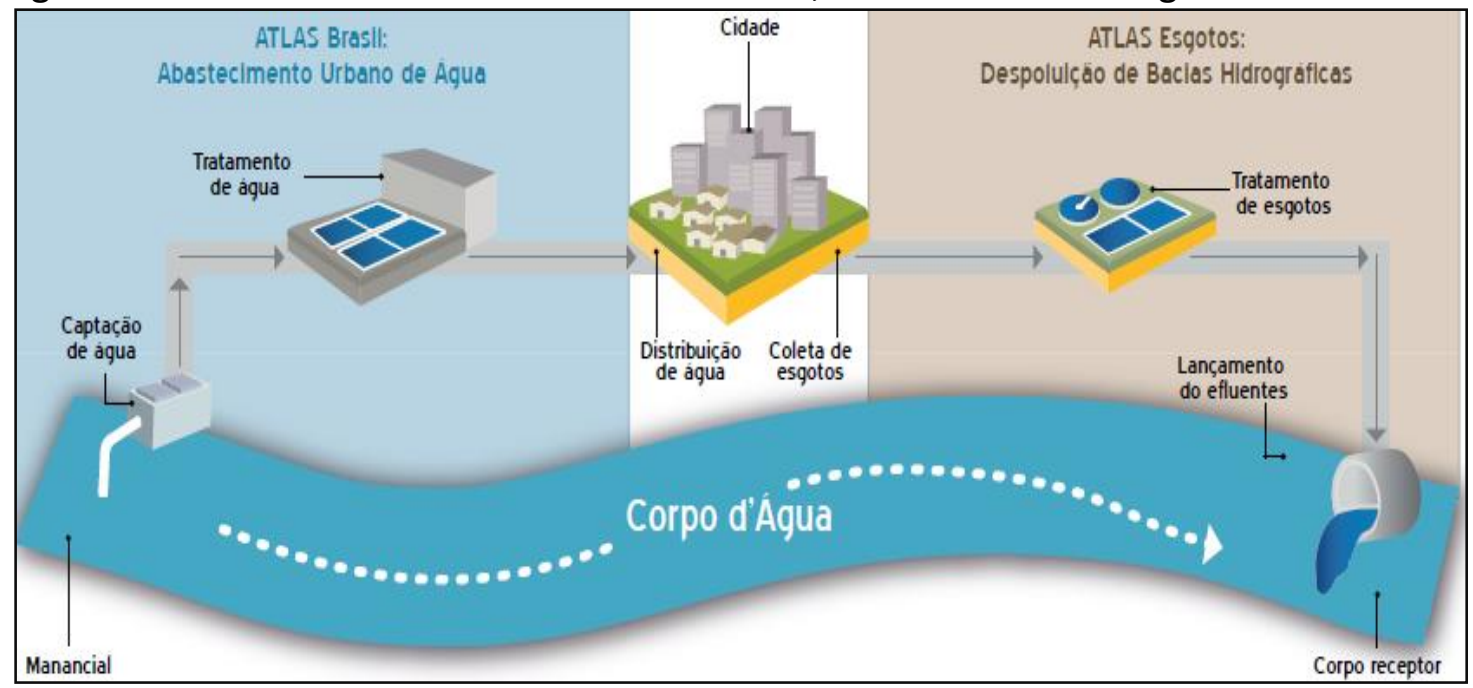

Fonte: adaptado Atlas Esgoto, 2017 
Conforme o Atlas Esgotos (2017) foram identificadas no Brasil 2.768 estações de tratamento de esgotos em operação em 1.592 cidades, com população atendida estimada em 71,7 milhões de habitantes.

Conforme pode ser se visualiza na Figura 3, nos estados da Região Sul 65\% da população tem atendimento considerado adequado, sendo que nas demais regiões os níveis de atendimento são inferiores: no Sudeste 59\%, Centro-Oeste 53\%, Nordeste 38\% e Norte $23 \%$. Ainda de acordo com o Atlas Esgotos (2017), o investimento necessário para universalizar os serviços de esgotamento sanitário no Brasil, no horizonte do ano de 2035, foi estimado em R\$ 149,5 bilhões, sendo as regiões Nordeste e Sudeste as maiores demandantes. Do investimento total no País, $44 \%$ foram previstos para aplicação em 840 municípios que requerem solução conjunta ou solução complementar. A população associada a esses municípios soma mais de 100 milhões de habitantes (Figura 3).

Figura 3 - Panorama geral de coleta e tratamento de esgotos no Brasil

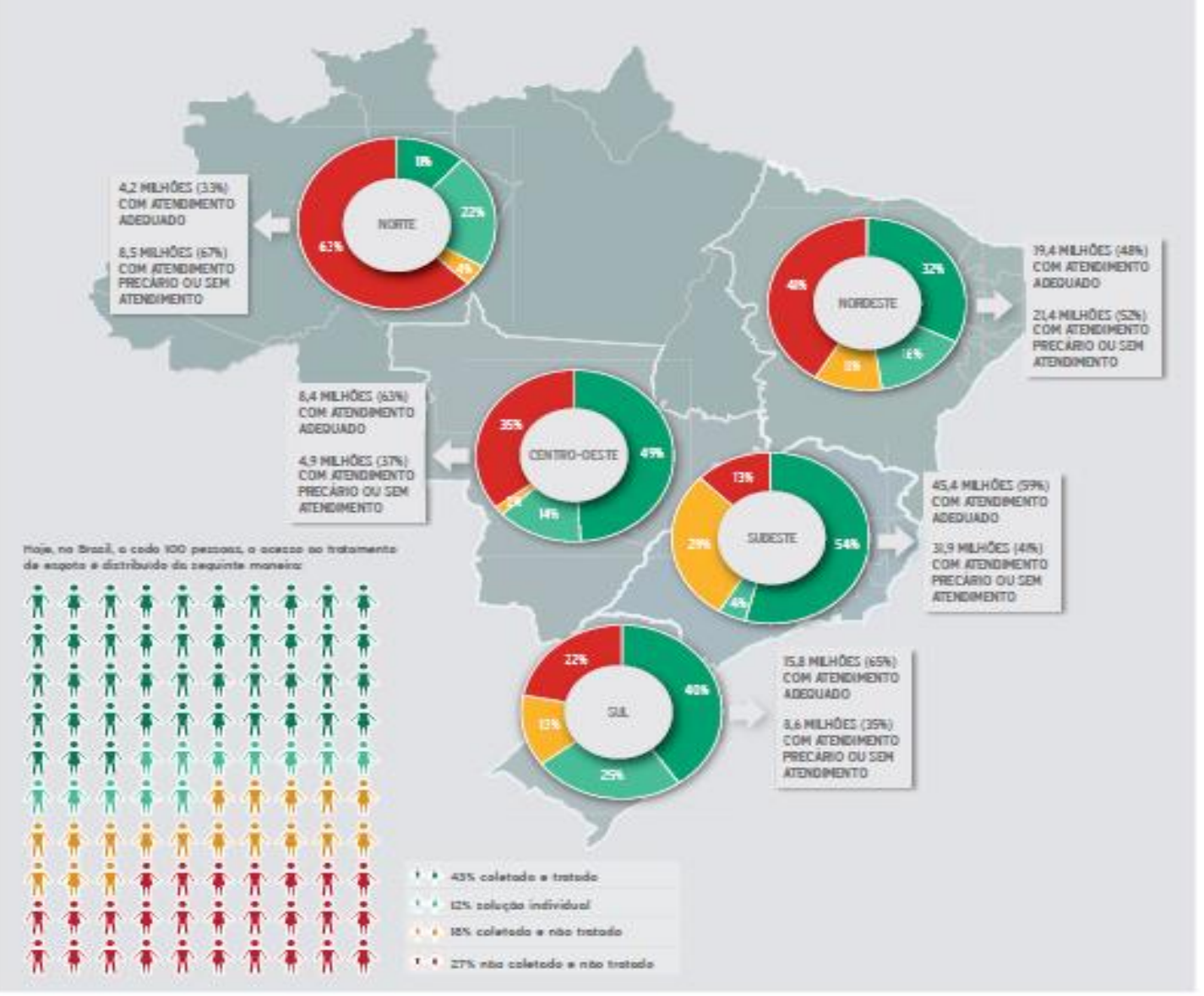

Fonte: adaptado Atlas Esgoto (2017) 
O assunto possui tamanha relevância sendo um dos 17 Objetivos de Desenvolvimento Sustentável (ODS) definidos em 2015 pela ONU. O ODS especificamente direcionado para este assunto é o Objetivo 6, que visa "Assegurar a disponibilidade e gestão sustentável da água e saneamento para todas e todos (Figura 4)".

Figura 4 - Composição do objetivo de desenvolvimento sustentável (ODS) no 6: Água limpa e Saneamento

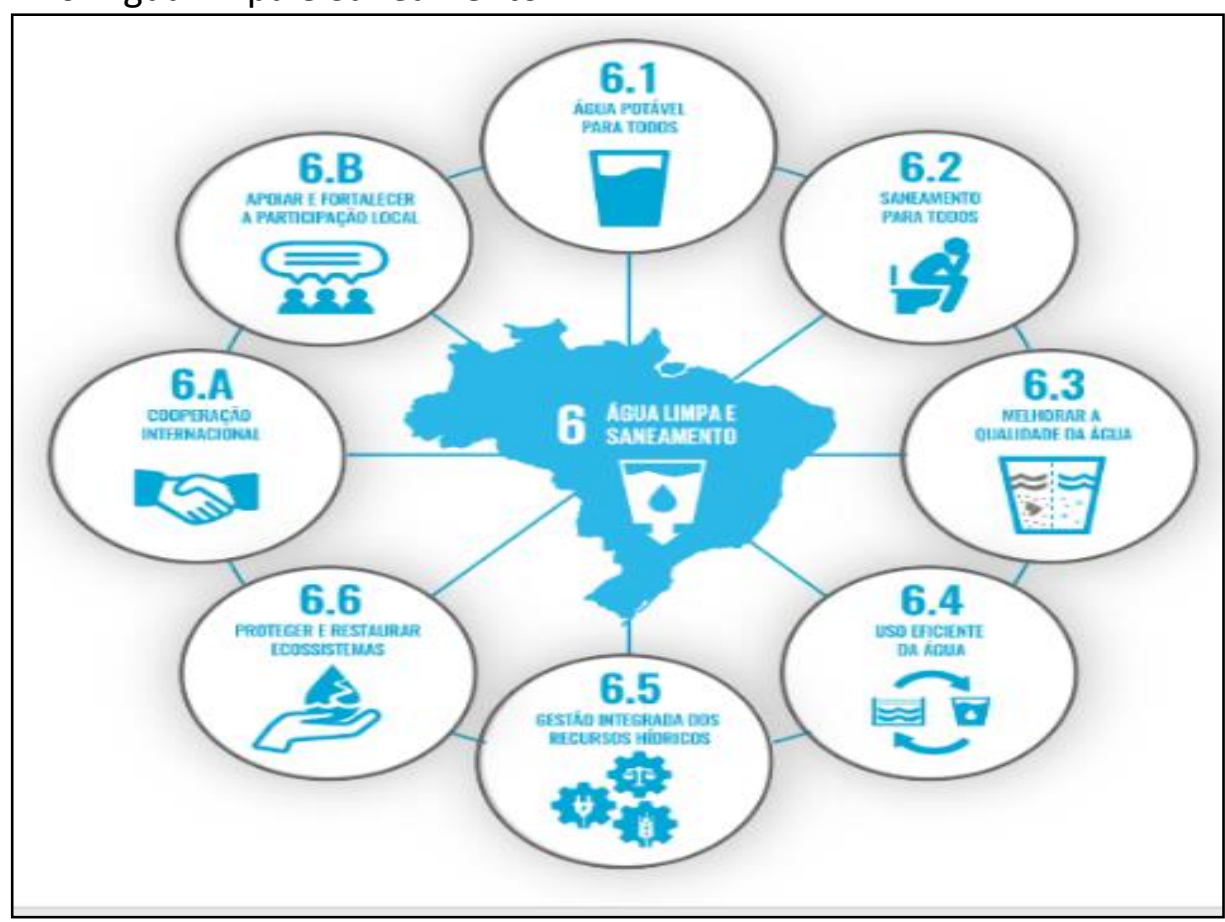

Fonte: Adaptado site ONU (2015)

Este objetivo se desdobra em outros oito itens, conforme se verifica na Figura 4, sendo mais especificamente, o item 6.2 que define: "Até 2030, alcançar o acesso a saneamento $e$ higiene adequados e equitativos para todos, e acabar com a defecação a céu aberto, com especial atenção para as necessidades das mulheres e meninas e daqueles em situação de vulnerabilidade".

De acordo com publicação da ONU, em 2015, 91\% da população global estava usando uma fonte de água potável aprimorada, comparado a 76\% em 1990. Contudo, 2,5 bilhões de pessoas não têm acesso a serviços de saneamento básico, como banheiros ou latrinas. O Brasil, como já verificado anteriormente, também apresenta situações problema e por sua vez o Estado do Rio Grande do Sul. Para dar conhecimento do objetivo e sua forma de obtenção, a próxima sessão tratará da metodologia adotada neste artigo. 


\section{Metodologia}

De acordo com o definido por Gerhardt e Silveira (2009) este trabalho está fundamentado em levantamento quantitativo de dados e as relações entre variáveis, de natureza aplicada, pois objetiva gerar conhecimentos para aplicação prática, dirigidos à análise de problemas específicos. Envolve verdades e interesses locais, com características explicativas e preocupa-se em identificar os fatores que determinam ou que contribuem para a ocorrência dos fenômenos (GIL, 2007). Quanto aos procedimentos haverá o levantamento Bibliográfico feito a partir da consulta e pesquisa de referenciais teóricos publicadas por meios escritos em fontes físicas ou outras mídias.

Para dar embasamento às avaliações realizadas foram utilizados os resultados obtidos a partir dos dados secundários das variáveis: "Taxa de Mortalidade Infantil (TMI)"; "População total atendida com esgotamento sanitário", "Volume de esgotos tratado", "Quantidade de ligações totais de esgotos" e "Índice de coleta de esgoto"; apresentados na Tabela 1, os quais foram coletados na Série Histórica do Sistema Nacional de Informações sobre Saneamento (SNIS) e do IBGE.

Os "dados de investimentos", "população" e "índice de esgotos coletados e tratados" foram obtidos no site do IBGE e no Sistema Nacional de Informações sobre Recursos Hídricos (SNIRH), apresentados na Tabela 2. Em ambos os casos foram consideradas as informações para 4 municípios da região metropolitana de Porto Alegre, inicialmente selecionados (Porto Alegre, Canoas, Esteio e Gravataí).

A relevância dos municípios escolhidos está na sua importância sócio, econômica e ambiental: os quatro municípios representaram em 2016 mais de 61\% do Valor Adicionado Bruto (VAB) da Região Metropolitana de Porto Alegre (RMPA) e de sua população. Não podemos esquecer que a RMPA é composta de 34 municípios, assim a participação destes é extremamente representativa, pois deixa para os demais (30) 39\% tanto do VAB quanto da população (IBGE, 2019).

Ambientalmente, conforme já salientado anteriormente, ambos fazem parte da bacia hidrográfica do Jacuí, Gravataí e do Sinos. Assim, qualquer problema ou investimento que ocorra em um dos municípios contribui para o desempenho em outro desta cadeia. Assim, a próxima etapa da pesquisa é realizar a análise dos dados referentes ao esgotamento sanitário e as demais variáveis escolhidas. 


\section{Análise dos dados}

Verifica-se, para a amostragem realizada de 2012 a 2017, que Esteio é o único município que apresenta um comportamento não linear de crescimento, com oscilações entre aumento e decréscimo no "Volume de esgotos tratado", sendo que os demais apresentaram ao longo deste mesmo período um crescimento nesta variável. Com relação ao indicador "Quantidade de ligações totais de esgotos", os quatro municípios avaliados têm um crescimento gradual, ao longo do período, observando um alinhamento com o indicador "População total atendida com esgotamento sanitário", na maioria dos casos (Quadro 1).

Quadro 1 - Dados sobre esgotamento sanitário e TMI para os municípios de Canoas, Esteio, Gravataí e Porto Alegre; de 2012 a 2017.

\begin{tabular}{|c|c|c|c|c|c|c|}
\hline Município & $\begin{array}{c}\text { Ano de } \\
\text { Referência }\end{array}$ & $\begin{array}{c}\text { ESO01 - } \\
\text { Pop. total atendida } \\
\text { com esgotamento } \\
\text { sanitário }\end{array}$ & $\begin{array}{c}\text { ES006- } \\
\text { Volume de } \\
\text { esgoto tratado }\end{array}$ & $\begin{array}{c}\text { ESO09 - } \\
\text { Quantidade de } \\
\text { ligações totais } \\
\text { de esgotos }\end{array}$ & $\begin{array}{l}\text { IN015_AE - } \\
\text { Índice de } \\
\text { coleta de } \\
\text { esgoto }\end{array}$ & $\begin{array}{l}\text { TMI - Taxa } \\
\text { de } \\
\text { Mortalidade } \\
\text { Infantil }(*)\end{array}$ \\
\hline \multirow{6}{*}{ Canoas } & 2012 & 58.261 & $2.279,67$ & 12.857 & 24,23 & 7,15 \\
\hline & 2013 & 72.430 & $2.727,90$ & 13.365 & 17,77 & 9,56 \\
\hline & 2014 & 74.564 & $3.461,00$ & 13.603 & 17,83 & 10,32 \\
\hline & 2015 & 88.457 & $4.781,80$ & 14.293 & 15,82 & 10,96 \\
\hline & 2016 & 103.657 & $6.043,02$ & 15.961 & 19,94 & 10,18 \\
\hline & 2017 & 113.661 & $6.205,45$ & 17.164 & 21,43 & 8,62 \\
\hline \multirow{6}{*}{ Esteio } & 2012 & 4.037 & 231 & 71 & 6,06 & 11,75 \\
\hline & 2013 & 4.042 & 134,06 & 71 & 26,38 & 13,81 \\
\hline & 2014 & 4.043 & 151,00 & 71 & 4,02 & 7,3 \\
\hline & 2015 & 4.042 & 127,01 & 71 & 2,54 & 14,01 \\
\hline & 2016 & 4.255 & 85,11 & 122 & 2,87 & 9,83 \\
\hline & 2017 & 4.431 & 118,92 & 188 & 3,02 & 13,93 \\
\hline \multirow{6}{*}{ Gravataí } & 2012 & 56.824 & $4.292,00$ & 18.192 & 47,2 & 6,45 \\
\hline & 2013 & 60.311 & $1.278,89$ & 18.790 & 26,19 & 7,8 \\
\hline & 2014 & 65.035 & $1.872,00$ & 19.904 & 27,24 & 7,53 \\
\hline & 2015 & 69.575 & $1.720,98$ & 20.901 & 20,25 & 6,96 \\
\hline & 2016 & 76.204 & $1.265,39$ & 22.406 & 25,11 & 8,36 \\
\hline & 2017 & 78.475 & $1.507,93$ & 22.789 & 25,87 & 11,45 \\
\hline \multirow{6}{*}{$\begin{array}{l}\text { Porto } \\
\text { Alegre }\end{array}$} & 2012 & 1.249 .542 & $18.678,85$ & 217.514 & 63,69 & 9,24 \\
\hline & 2013 & 1.312 .228 & $18.181,27$ & 227.405 & 63,83 & 9,27 \\
\hline & 2014 & 1.316 .399 & $33.666,87$ & 230.764 & 63,27 & 9,75 \\
\hline & 2015 & 1.324 .750 & $66.395,08$ & 234.940 & 61,13 & 9,23 \\
\hline & 2016 & 1.332 .822 & $63.675,47$ & 240.231 & 63,32 & 9,02 \\
\hline & 2017 & 1.339 .862 & $58.713,37$ & 243.280 & 64,14 & 8,98 \\
\hline
\end{tabular}

Fonte: Adaptado SNIS (2019) e IBGE (2019)

Nota: $(*)$ Os dados da TMI foram obtidos no sistema do IBGE, disponível em https://cidades.ibge.gov.br. 
A verificação dos números absolutos apresentados pode inferir, inicialmente, que não há informações suficientes para uma avaliação efetiva ou que defina uma possibilidade de relação entre as variáveis analisadas. No entanto ao realizar uma avaliação, considerando as relações entre algumas destas com base nos dados disponíveis verifica-se que a razão entre a "População total atendida com esgotamento sanitário" e o "Índice de coleta de esgoto", possui uma tendência de crescimento ao longo dos anos em todos os municípios avaliados, considerando a projeção linear dos dados no período avaliado (2012 a 2017), muito embora seja importante comentar que a taxa de crescimento destes não é igual, bem como a força de correlação entre os indicadores, identificado através do $\mathrm{R}^{2}$ obtido em cada uma das projeções lineares realizadas, cada um possuindo características específicas e inclinação diferenciada da reta de tendência linear (Figura 5). No caso específico do município de Porto Alegre se utilizou a constante de divisão 3, a fim de facilitar sua visualização.

Figura 5 - Razão entre indicadores: população total atendida e índice de coleta de esgoto

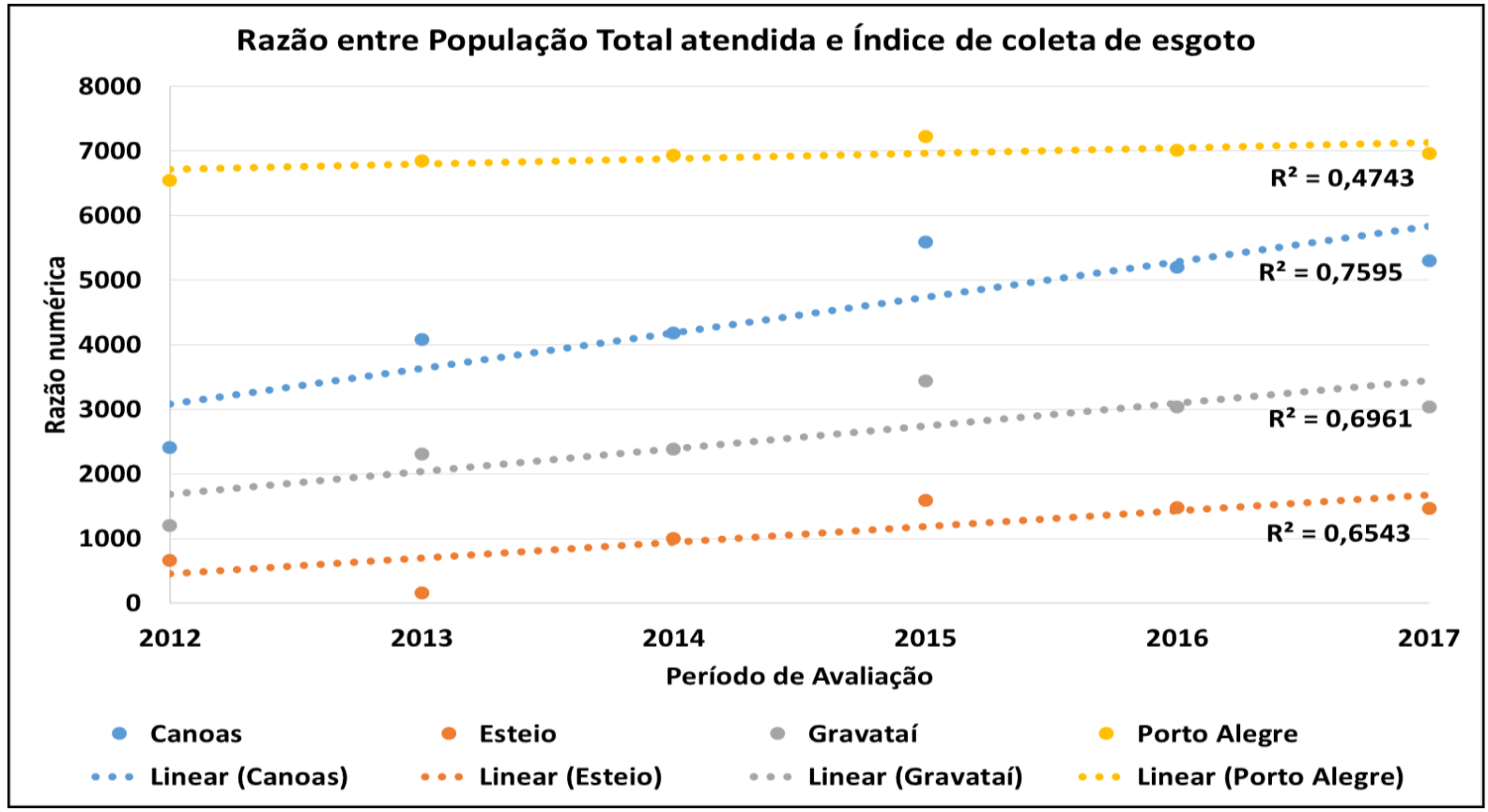

Fonte: autores (2019)

Ainda com base nos dados apresentados no Quadro 1, foi realizada uma análise e o resultado demonstra que quanto maior o resultado da razão entre o "Índice de coleta de esgoto" e a "Taxa de mortalidade infantil" melhor é o desempenho da cidade, ou seja, onde é maior o índice da coleta de esgoto haverá menor Taxa de Mortalidade Infantil associada. O resultado desta razão será um valor crescente maior que zero tendendo a 100. Esta relação tem como 
objetivo "quanto maior melhor" e o resultado da avaliação para os 4 municípios pode ser visualizado na Figura 6.

Figura 6 - Relação entre índice de coleta de esgoto e TMI

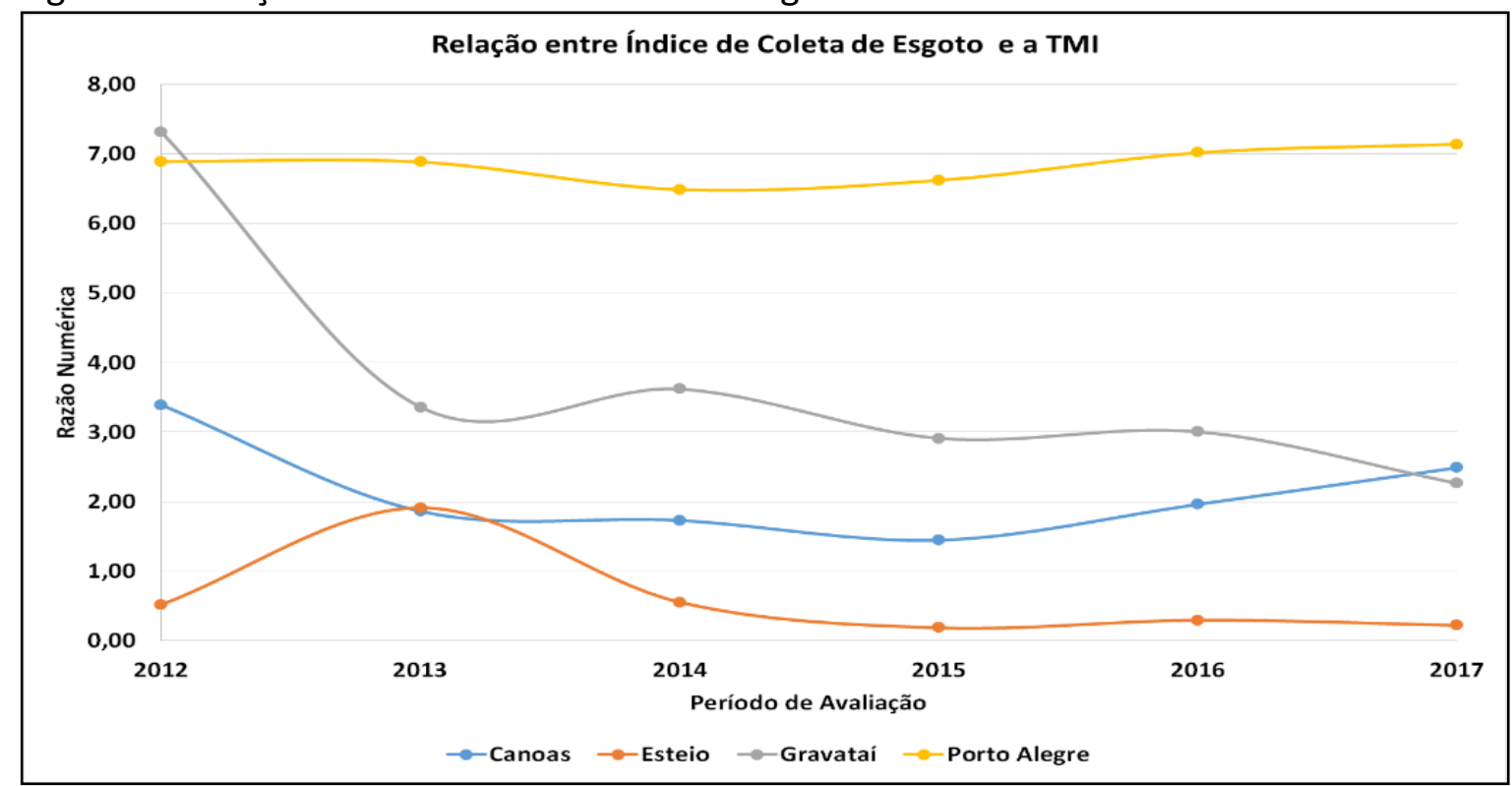

Fonte: autores (2019)

Conforme os dados apresentados no Quadro 2, abaixo, ao analisar a relação entre o indicador "Investimento Previsto Total (R\$ bilhões)" para coleta e tratamento de esgotos e o indicador "População Urbana" dos municípios avaliados, se verifica uma proximidade dos valores "per capta" em R\$ para os municípios de Porto Alegre e Canoas.

Quadro 2 - Investimentos e Índice de Tratamento de esgotos para os municípios de Canoas, Esteio, Gravataí e Porto Alegre (dados referentes a 2013)

\begin{tabular}{|l|r|r|r|r|}
\hline & Porto Alegre & \multicolumn{1}{c|}{ Canoas } & \multicolumn{1}{c|}{ Esteio } & \multicolumn{1}{c|}{ Gravataí } \\
\hline População urbana & 1.467 .816 & 338.531 & 83.584 & 256.223 \\
\hline Índice de atendimento coletado e não tratado & $52,34 \%$ & $4,53 \%$ & $53,20 \%$ & $0,00 \%$ \\
\hline Índice de atendimento coletado e tratado & $47,06 \%$ & $67,72 \%$ & $8,20 \%$ & $25,30 \%$ \\
\hline Índice de atendimento não coletado & $0,00 \%$ & $7,00 \%$ & $9,10 \%$ & $58,30 \%$ \\
\hline Índice de atendimento solução individual & $0,60 \%$ & $20,75 \%$ & $29,50 \%$ & $16,40 \%$ \\
\hline Investimento em coleta (R\$ bilhões) & $\mathrm{R} \$ 0,13$ & $\mathrm{R} \$ 0,09$ & $\mathrm{R} \$ 0,03$ & $\mathrm{R} \$ 0,22$ \\
\hline Investimento em tratamento (R\$ bilhões) & $\mathrm{R} \$ 0,61$ & $\mathrm{R} \$ 0,06$ & $\mathrm{R} \$ 0,02$ & $\mathrm{R} \$ 0,06$ \\
\hline Investimento previsto total (R\$ bilhões) & $\mathrm{R} \$ 0,74$ & $\mathrm{R} \$ 0,15$ & $\mathrm{R} \$ 0,05$ & $\mathrm{R} \$ 0,28$ \\
\hline Investimento total (R\$ /per capta) & $\mathrm{R} \$ 504,15$ & $\mathrm{R} \$ 428,68$ & $\mathrm{R} \$ 611,41$ & $\mathrm{R} \$ 1.077,07$ \\
\hline
\end{tabular}

Fonte: IBGE (2019)

Verifica-se na Figura 7 que os maiores valores (em $\mathrm{R} \$$ ) de investimentos per capta foram em Esteio e, mais significativo ainda, para Gravataí (Figura 7). 
Figura 7 - Investimento "per capta" para os municípios de Canoas, Esteio, Gravataí e Porto Alegre (dados de 2013).

\begin{tabular}{|c|c|c|c|c|}
\hline \multicolumn{5}{|c|}{ Investimento "per capta" - Base 2013} \\
\hline \multicolumn{4}{|l|}{$\mathrm{R} \$ 1.000,00$} & \\
\hline \multicolumn{4}{|l|}{ R\$ 800,00} & \\
\hline \multicolumn{4}{|l|}{$R \$ 600,00$} & \\
\hline \multicolumn{4}{|l|}{$\mathrm{R} \$ 400,00$} & \\
\hline \multicolumn{4}{|l|}{$R \$ 200,00$} & \\
\hline RS - & Porto Alegre & Canoas & Esteio & Gravataí \\
\hline Eérie1 & $\mathrm{R} \$ 504,15$ & $\mathrm{R} \$ 428,68$ & $\mathrm{R} \$ 611,41$ & $\mathrm{R} \$ 1.077,07$ \\
\hline
\end{tabular}

Fonte: Dados da pesquisa feita pelos autores (2019)

Ainda avaliando e correlacionando as informações coletadas e apresentadas no Quadro 2, pode ser visualizado na Figura 8 os índices (percentuais) de esgoto coletado e tratado nos 4 municípios, com destaque para o município de Canoas, com um percentual de 68\%, o maior índice entre os municípios, comparados para o ano de 2013.

Figura 8 - Índice de esgoto coletado e tratado nos 4 municípios (dados de 2013).

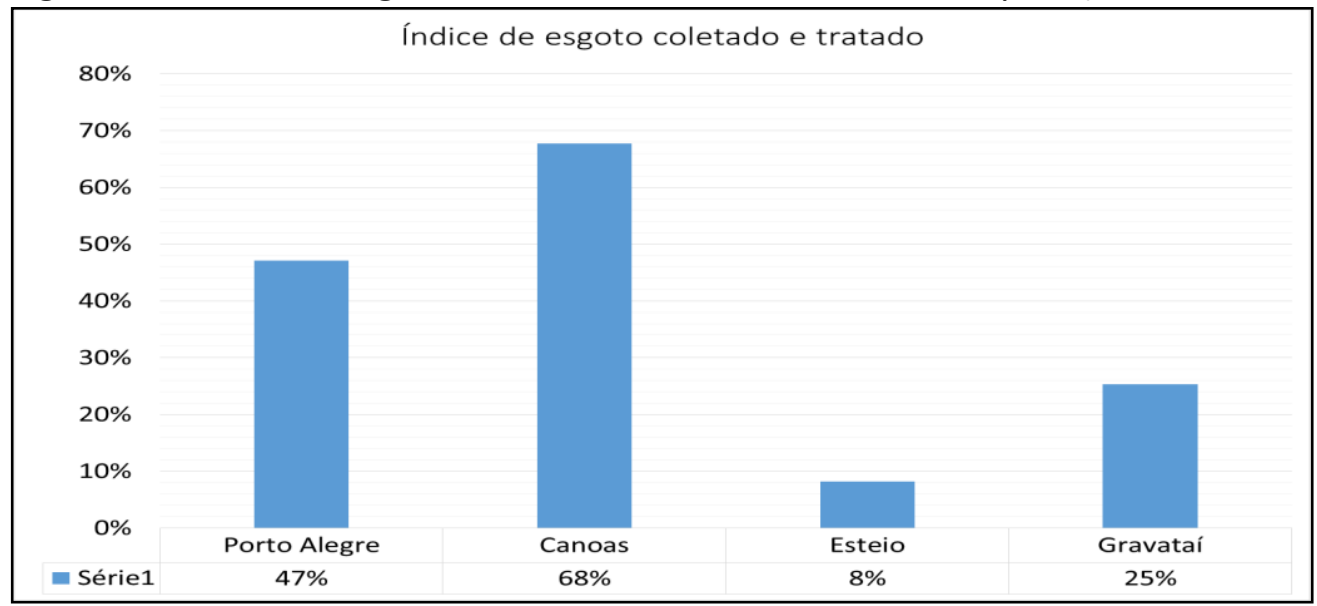

Fonte: Os autores (2019)

Como forma de identificar a potencialidade das ações que, em se tratando de assuntos referentes ao tema do saneamento são sempre de longo prazo e consequentes de diversas atividades que necessitam de amadurecimento, este trabalho propõe avaliar a correlação entre "índice de esgoto coletado e tratado" base 2013, considerando que é o último dado disponível e inferindo que este índice no mínimo manteve-se estável no eixo de tempo com a "Taxa de 
mortalidade infantil", base 2017, também dado mais atual disponível, ou seja avaliar o efeito acumulativo de 4 anos dos índices de coleta e tratamento e seu impacto na TMI. Os dados analisados através de regressão linear são apresentados no Quadro 3.

Quadro 3 - Taxa de Mortalidade Infantil (2017) e Índice de atendimento Coletado e tratado (2013) para os municípios de Canoas, Esteio, Gravataí e Porto Alegre.

\begin{tabular}{|l|r|r|r|r|}
\hline & Porto Alegre & Canoas & Esteio & Gravataí \\
\hline Mortalidade Infantil (1000 nascidos vivos) 2017 & 9,27 & 9,56 & 13,81 & 7,8 \\
\hline Índice de atendimento Coletado e tratado (2013) & $47,06 \%$ & $67,72 \%$ & $8,20 \%$ & $25,30 \%$ \\
\hline
\end{tabular}

Fonte: IBGE (2019)

Conforme se verifica Figura 9, a regressão linear considera: no eixo y os resultados da "Taxa de mortalidade infantil" e no eixo x "índice de esgoto coletado e tratado" (ou de esgotamento sanitário) apresenta um resultado de $\mathrm{R}^{2}=0,9018$, indicando que há uma forte correlação entre estes dados. Verifica-se que Esteio, com aproximadamente $10 \%$ de esgotamento sanitário, tem a maior taxa de mortalidade infantil entre os quatro municípios da pesquisa. No outro extremo estão Canoas e Porto Alegre, com as menores taxas de mortalidade infantil e com percentual de esgotamento, respectivamente de $50 \%$ e $70 \%$ (Figura 9).

Figura 9 - Relação entre taxa de mortalidade infantil/índice de esgotamento sanitário

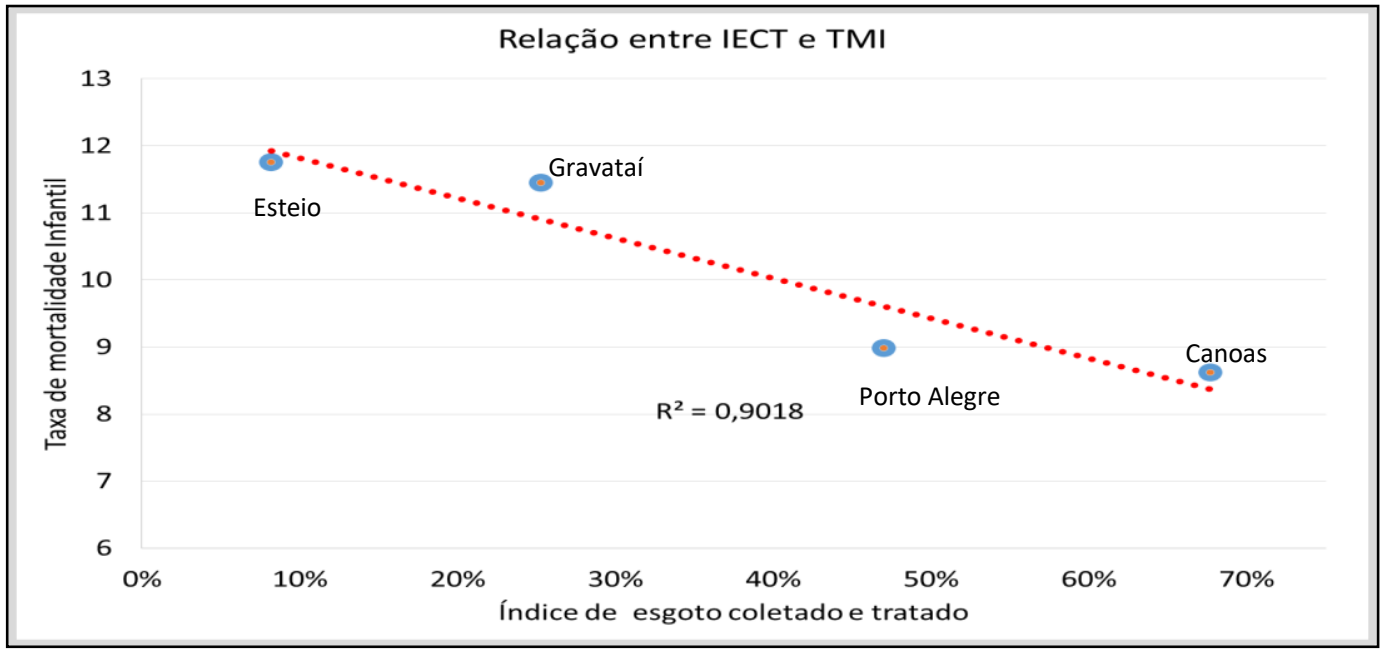

Fonte: autores (2019)

Isto pode ainda ser reforçado ao se verificar no Quadro 4 que o valor obtido para análise de correlação é de - 0,950, indicando que há uma correlação inversa entre as variáveis que pode ser considerada forte, pois o limite de máxima é igual a 1. 
Quadro 4 - Correlação entre os indicadores

\begin{tabular}{|c|c|c|}
\hline & $\begin{array}{c}\text { \% de atendimento } \\
\text { adequado }\end{array}$ & TMI \\
\hline $\begin{array}{c}\text { \% de atendimento } \\
\text { adequado }\end{array}$ & 1 & \\
\hline TMI & $-0,950$ & 1 \\
\hline
\end{tabular}

Fonte: autores (2019)

Este resultado de $\mathrm{R}^{2}$ reforça as citações e os comentários identificados nos referenciais consultados e anteriormente relatados de que quanto maior a taxa de esgotamento sanitário em uma cidade, menor será a taxa de mortalidade infantil. O valor de correlação que é avaliada no intervalo de zero a 1 , indica que o resultado quanto mais próximo de 1 , maior a força na correlação entre as variáveis.

\section{Considerações finais}

A falta de água e esgotamento sanitário afeta diretamente a saúde da população infantil. As doenças como diarreia, malária e pneumonia estão entre as causas mais comuns de mortes de crianças entre um mês e cinco anos, segundo a OMS.

As análises dos dados e as correlações propostas indicam que, nos períodos analisados, para os indicadores selecionados e os municípios avaliados há uma relação entre as ações e atendimentos referentes ao tratamento adequado dos esgotos e a taxa de mortalidade infantil. Em todos os casos deste estudo se identifica que quanto maior a disponibilidade e adequação dos serviços, maior os investimentos realizados, menor é a TMI - taxa de mortalidade infantil nos municípios avaliados.

O resultado de $\mathrm{R}^{2}=0,9018$ para a regressão linear é um dado que indica que não é mera suposição ou teoria que as condições adequadas de saneamento estão diretamente relacionadas com os fatores de saúde da população, neste caso específico a Taxa de mortalidade infantil, da mesma forma que se verifica que nas cidades onde é maior a população atendida pelos serviços de saneamento, ao longo do tempo, se verifica também um reflexo positivo de diminuição da TMI, suportado ainda pelo valor obtido na análise de correlação que foi de $-0,950$, indicando que há forte correlação inversa entre as variáveis. 
Importante destacar que a análise pontual, sem considerar uma série histórica ou o tempo necessário para avaliar os resultados de eventuais ações ou empreendimentos neste segmento, pode ocasionar deduções equivocadas.

De forma positiva se identificam ações por parte dos principais agentes envolvidos no assunto, conforme divulgação da Companhia Riograndense de Saneamento - CORSAN (2019) através de seu site, que a concessionária recebeu três propostas de empresas interessadas em participar da licitação da Parceria Público-Privada (PPP) do Saneamento, e que para final de 2019 início de 2020 está marcado o leilão da PPP, no qual serão conhecidas as propostas comerciais. A PPP visa agilizar a universalização do esgotamento sanitário na Região Metropolitana de Porto Alegre, com um investimento total de $R \$ 2,23$ bilhões, divididos em obras em execução pela Corsan no montante de $\mathrm{R} \$ 370$ milhões e investimentos do parceiro privado de $\mathrm{R} \$ 1,86$ bilhão.

Especificamente para o município de Porto Alegre, conforme reportagem do jornal Correio do Povo em 06/09/2019 foi formado consórcio pelas empresas Hidroconsult, Houer e Machado Meyer o qual venceu o pregão eletrônico da Parceria Público-Privada (PPP) do saneamento básico, realizado pelo Banco Nacional de Desenvolvimento Econômico e Social (BNDES), com proposta de $\mathrm{R} \$ 1,67$ milhão. O grupo venceu a concorrência para iniciar os estudos de viabilização do projeto.

Por fim, é imperativo que o poder público esteja consciente de seu papel, mas também se ressalta, com a devida importância, a necessidade de conscientização da população em geral das suas responsabilidades e influência nestes indicadores. Isto porque, a observância e o zelo pelas condições e qualidade dos locais de habitação também são tarefas que cabem aos cidadãos em sua interação política e de cidadania.

\section{Referências}

AGÊNCIA NACIONAL DE ÁGUAS (ANA). Revista Balanço das Águas, 2018 - Disponível em. http://balancodasaguas.ana.gov.br/balanco/pt/home. Acesso em: 01/12/2019.

Sistema Nacional de Informações sobre Recursos Hídricos (SNIRH) ATLAS ESGOTOS Despoluição de Bacias Hidrográficas. Disponível em: http://www.snirh.gov.br/portal/snirh/snirh-1/atlas-esgotos. Acesso em: 01/11/2019. BRIÃO, Vandré Barbosa et. all. Reverse osmosis for desalination of water from the Guarani Aquifer System to produce drinking water in southern Brazil. Desalination, vol. 344, p. 402-41, 1 July 2014. Disponível em: https://www.sciencedirect.com/science/article/abs/pii/S0011916414002112. Acesso em: $12 / 11 / 2019$. 
BRASIL. SENADO FEDERAL. Os muitos males provocados pela falta de saneamento. Em Discussão, Ano 7, no 27, maio 2016. Disponível em:

https://www12.senado.leg.br/emdiscussao/edicoes/saneamento-basico/saneamento/osmuitos-males-provocados-pela-falta-de-saneamento. Acesso em: 02/11/2019.

COMPANHIA RIOGRANDENSE DE SANEAMENTO (CORSAN). Companhia recebe três propostas na licitação da PPP do Saneamento. Disponível em: http://www.corsan.com.br/corsan-recebetres-propostas-na-licitacao-da-ppp-do-saneamento. Publicação: 25/11/2019. Acesso em: $27 / 11 / 2019$

CORREIO DO POVO._Definido consórcio vencedor que fará estudo de PPP do saneamento de Porto Alegre. Disponível em: https://www.correiodopovo.com.br/not\%C3\%ADcias/geral/ definido-cons\%C3\%B3rcio-vencedor-que-far\%C3\%A1-estudo-de-ppp-do-saneamento-de-portoalegre-1.364010. Publicação: 06/09/2019. Acesso em: 27/11/2019

GERHARDT, Tatiana Engel e SILVEIRA, Denise Tolfo (Org). Métodos de pesquisa. Porto Alegre: Editora da UFRGS, 2009. Disponível em:

http://www.ufrgs.br/cursopgdr/downloadsSerie/derad005.pdf. Acesso em: 18/12/2019.

GIL, Antonio C. Como elaborar projetos de pesquisa. 4ạ ed. São Paulo: Atlas, 2007.

INSTITUTO BRASILEIRO DE GEOGRAFIA E ESTATÍSITICA (IBGE)- IBGE Cidades - Municípios. Disponível em https://cidades.ibge.gov.br/. Acesso em: 0511/2019.

MENEZES, Tatiane Almeida De; UCHOA, Frederico. Mortalidade infantil, saneamento básico e o impacto da saúde sobre o crescimento econômico brasileiro. In $39^{\circ}$ Encontro Nacional De Economia Da Associação Nacional Dos Centros De Pós-Graduação Em Economia - (ANPEC). Foz do Iguaçu, 6 a 9 de dezembro de 2011. Disponível em:

https://www.anpec.org.br/encontro/2011/inscricao/arquivos/0005878a904f5f7a41f452f94d64d7f108a.pdf. Acesso em: 03/11/2019.

ORGANIZACCÃO MUNDIAL DA SAÚDE (OMS). Os muitos males provocados pela falta de saneamento. Disponível em: https://www12.senado.leg.br/emdiscussao/edicoes/. Acesso em: 03/11/2019.

ORGANIZAÇÃO DAS NAÇÕES UNIDAS (ONU). Objetivos do Desenvolvimento Sustentável. Disponível em: https://nacoesunidas.org/pos2015/. Acesso em: 03/11/2019.

MOREIRA, Giuliana. Dia Mundial da Água 2019 - 'Não deixar ninguém para trás'. Nações Unidas Brasil. Publicado em 22/03/2019. Disponível em: https://nacoesunidas.org/artigo-diamundial-da-agua-2019-nao-deixar-ninguem-para-tras/. Acesso em: 17/12/2019.

SILVA, Valéria Andrade; ESPERIDIÃO, Fernanda. Saneamento básico e seus impactos na mortalidade infantil e no desenvolvimento econômico da região Nordeste. Scientia Plena v.13, no 10, p. 1- 7, 2017. Disponível em: https://www.scientiaplena.org.br/sp/article/view/3757. Acesso em: 18/01/2020.

SISTEMA NACIONAL DE INFORMAÇÕES SOBRE SANEAMENTO (SNIS)._Painel de informações sobre o saneamento. Disponível em http://www.snis.gov.br/diagnostico-agua-e-esgotos. Acesso em: 03/11/2019.

SISTEMA NACIONAL DE INFORMAÇÕES SOBRE SANEAMENTO (SNIS). Série Histórica. Ministério do Desenvolvimento Regional. Disponível em: http://app4.cidades.gov.br/serieHistorica/\#. Acesso em: 03/11/2019. 
SOARES, Sérgio R. A. et. all. Relações entre saneamento, saúde pública e meio ambiente:

elementos para formulação de um modelo de planejamento em saneamento. Caderno de Saúde Pública, Rio de Janeiro, vol.18, n.6, p.1713-1724, 2002. Disponível em:

http://www.scielo.br/scielo.php?script=sci arttext\&pid=S0102-

311X2002000600026\&lng=en\&nrm=iso\&tIng=pt. Acesso em: 17/01/2020.

SUZIN, Raphaela. Número de cidades gaúchas com políticas para saneamento básico cresce 350\% em sete anos. Jornal Correio do Povo, atualizado em 21/09/2018. Disponível em: https://www.correiodopovo.com.br/notícias/geral/. Acesso em: 07/11/2019.

TAMBOSI, José Luiz. Remediação de efluente da indústria de papel e celulose por processos oxidativos avançados e coagulação férrica. Dissertação apresentada ao curso de Pós-graduação em Engenharia Química do Centro Tecnológico da Universidade Federal de Santa Catarina Florianópolis, agosto de 2005. Disponível em:

https://repositorio.ufsc.br/handle/123456789/102993. Acesso em: 18/11/2019.

TUNDISI, José Galizia. Recursos hídricos no futuro: problemas e soluções. Estudos Avançados. v.22, n.63, p.7-16, 2008. Disponível em: http://www.scielo.br/pdf/ea/v22n63/v22n63a02.pdf. Acesso em: 27/11/2019. 